\title{
13TH ANNUAL INTERNATIONAL AFIR COLLOQUIUM
}

\author{
Wednesday afternoon, 17 - Friday night, 19 September 2003 \\ MECC - Maastricht - The Netherlands
}

Het Actuarieel Genootschap, the Dutch Actuarial Society, is pleased to welcome participants and partners to Maastricht, the oldest city in The Netherlands; wellknown since the signing of the 'Treaty of Maastricht' in 1992. The city offers both excellent congress facilities and ample opportunities for social activities and is therefore an ideal venue for the International AFIR Colloquium in 2003.

\section{Call for papers}

The Scientific Committee invites authors to submit papers for the 13th International AFIR Colloquium. Detailed instructions on the format of papers can be found on the 'Call for papers' website page. The deadline for submitting scientific papers in their final form will be 1 April 2003.

\section{Topics}

Although papers can be submitted on any subject covered by AFIR, the Scientific Committee has chosen three main subject areas for papers as listed below. We would like to stress that they are nót restricted to Pensions and Insurance, but should be looked at in the broader context of AFIR, including Banking and Industry.

\section{Asset Classification}

- What asset categories should be distinguished

- What are their features

- How can they be modeled

\section{Market Valuation of Liabilities}

- What is the definition of market value of liabilities

- How is market value of liabilities related to assets

- What are the risk characteristics of such a market value

\section{Risk Measurement and Management}

- How is Risk Measurement and Management defined

- What are the leading indicators besides Investment Risk

- What techniques can be used

\section{Conference venue}

When it comes to a succesful conference, there are two essential factors: the quality of the facilities and the quality of the environment. In Maastricht, these two factors combine perfectly. The Maastricht Exhibition \& Congress Centre (MECC) is one of the most modern conference centres in Europe. And Maastricht is a very attractive city. This combination makes Maastricht the perfect conference venue. 


\section{International reputation}

Maastricht, the southernmost city in the Netherlands, is easy to reach by car, train or aeroplane. Situated in the heart of Europe, Maastricht is bordered by Belgium and Germany with France nearby. It is a place where many different European cultures meet and with the signing of the Maastricht Treaty it has expanded it's Euregional function.

\section{Everything under one roof}

The MECC offers congress facilities, with plenty of three and four star hotel accommodation on site. Outside conference sessions, we will make sure you get a good taste of Maastricht and Zuid-Limburg.

\section{www.afir2003.nl}

Visit our website www.AFIR2003.nl for up-to-date information on the 13th AFIR Colloquium 2003.

Organising Committee

Hugo Berkouwer (chairman), Pari Kandhai,

Marcel Thijssen, Inge Huizinga

\section{Scientific Committee}

Ruud Kleynen (chairman), Ineke Schoenmaker

and a number of (inter)nationally renowned scientists, to be announced on the website shortly. 